\title{
Conceptualisation of the consequences of land use decisions on water resources in the central region of South Africa: an agent based modelling perspective
}

\author{
YE WOYESSA, WA WeLDERUFAEL AND JDM KINYUA*
}

\begin{abstract}
Over the past few decades, numerous researchers have improved measurements of land use change through representation of much more complex processes of land use and its impact on water resources. Understanding the causes of land use change has moved from a simplistic representation of a few driving forces to a much more detailed understanding that involves situation-specific interactions among a large number of factors at different spatial and temporal scales using agent-based models. The agentbased perspective is centred on the general nature and rules of land use decision making by individuals and represents the motivations behind decisions and the external factors that influence decisions about land use. In this paper, an attempt is made to conceptualise the social and biophysical interactions as the driving forces that lead to decisions of land use, and its potential impact on water resource, including factors such as interventions and technologies that influence the decision of land use change in rural agricultural areas. The development of the conceptual model was done through a series of meetings and workshops and by visualising the relationships between the different factors, such as biophysical and socio-economic factors, using a brain mapping technique. The resulting conceptual model illustrates the main domains of the environment, the socioeconomic factors, and captures all the factors and their interaction that lead to decision in land use change. The socio-economic factors and their interaction will be captured by the ABM module while the biophysical factors that have direct impact on runoff and stream flow could be handled by the hydrologic module which will then be integrated into the ABM model. This, however, is a primary effort in the development of an ABM within the Modder River Basin system and needs continues refinement for optimum functionality and simulation of the real world.
\end{abstract}

Keywords: Agent-based model, Agent, conceptual model, land use, water

Disciplines: Soil science, Management Studies, Engineering, Geography

* Y.E. Woyessa and W.A. Welderufael are from the School of Civil Engineering and Built Environment at the Central University of Technology, Free State J.D.M. Kinyua is from the School of Information and Communication Technology at the Central University of Technology, Free State. 


\section{Introduction}

The planning and management of water resources at a catchment level is becoming a widely adopted approach (Becu et al., 2003; Jewitt et al., 2004). This approach enables one to monitor the water balance of a hydrologically isolated catchment (Calder, 2003; Jewitt et al., 2004). The delineated surface environment helps to reconcile the input and output of water in the system. In addition, the different biophysical and social interactions and processes that are taking place and that have a significant effect on water resources can be spatially identified (Woyessa et al., 2006a).

This also makes it possible to rationally conceptualize impacts on water resources, such as rivers, lakes, springs and communal irrigation canal systems located on a catchment and which are considered communal properties and known as common pool resources (CPR) (Ostrom et al., 1994; Deadman, 1999). Ostrom et al. (1994) defines CPR as natural or man-made resource systems that are sufficiently large so as to make it costly (but not impossible) to exclude potential beneficiaries from obtaining benefits from its use.

In a given catchment the natural resource in general and the water resource in particular can be affected by several factors, such as biophysical (precipitation, temperature, ground water flow, vegetation, soil type and topography) and socio-economic factors (institutions, technological developments, market, etc.). These in turn have a combined effect on land use and impacts on the water resource. The change in land use takes place as a result of decisions by land users which in itself is a consequence of the interactions between the socioeconomics and biophysical factors.

Different land types and associated contrasting soils contribute to differences in runoff, surface evaporation and recharge that take place on a catchment scale. The direct response of a rainfall event which is runoff may route the natural canal system and discharges at the outlet of a catchment or harnessed by a reservoir for different uses.

The volume of water stored in a reservoir is therefore partly dependent on the runoff generated from the different land uses. A change in land use could, therefore, affect the proportion of runoff produced from the different land use practises. However, a change in land use depends on the decisions taken by the land manager (Feuillette et al., 2003).

Individual land owners operating in a catchment undertake complex processes of interaction between the natural environment and the socio-economic situation. The biophysical input largely relates to the climate and soil properties; and they are largely beyond human control. Thus, the final decision to change land use can only be 
reached after a complex interaction of socioeconomic and environmental factors have been considered. For a given catchment, the detailed process of these interactions can be rationally conceptualised in a multidisciplinary way.

Interventions such as rainwater harvesting (RWH) could be one such decision of land use which is brought about through a complex process of interactions between agents (researcher/extension worker and the farmer), and as a consequence of soil type (environment) and accepted land use practices. Thus, change of land use to RWH will result in a decrease in rainfall runoff to rivers and to dams. Similarly, an increase in irrigated land results in increased withdrawals of water from the river system which in turn results in decreased amount of water entering into storage dams. Such decisions by farm managers to change land use are attained after a process of complex deliberations that take into account current farming practices, socioeconomics factors and the environment.

The new paradigm in land use decision making requires greater consideration of the complex human (agents) and environment interactions. In the broader sense, land use and cover change is a result of a human decision that emerges from the interactions of agents, biophysical inputs and the environment (Lambin et al., 2003).

Couclelis (2001) acknowledges that human decision making plays a major role in land use change. Land use change can bring about a significant effect on a catchment water resource. For instance, Woyessa et al. (2006b) demonstrated, using an empirical model, that a decrease in runoff contribution of $25.3 \%$ would occur if all suitable lands for RWH is put under cultivation in C52A (one of the quaternary catchments in the Modder river basin) which would most likely affect the downstream water supply.

Over the past few decades, numerous researchers have improved measurements of land use change using predictive models that can describe significantly more complex processes of land use and its impact on water resources (Feuillette, et al., 2003; Lambin et al., 2003). Understanding the causes of land use change has moved from simplistic representations of few driving forces to a much more profound understanding that involves situation-specific interactions among a large number of factors at different spatial and temporal scales.

These models have modules for the socioeconomic as well as for the biophysical inputs (Feuillette et al., 2003). Agent-based models developed for land use/cover change are equipped with two important key components (Berger et al., 2002): the cellular model that represents the landscape under study; and an agent based model $(\mathrm{ABM})$ that represents human decision making and interactions. 
According to Berger et al. (2002) ABM consists of autonomous decision making entities (agents), an environment through which agents interact, rules that define the relationship between agents and their environment, and rules that determine sequence of actions in the model.

Furthermore, Feuillette et al. (2003) identifies three classes of models that deal with Common Pool Resources (CPR), namely: (1) physical models centred on the dynamics of resources and that consider demand as a given parameter; (2) agronomic, economic or agro-economic models centred on demand and that attempt to adapt water demand to a fixed amount of resource; and (3) mixed models that represent interaction between the functioning of physical and socio-economic systems through a single mathematical language. This is done through the coupling of several models or through multi-agent systems (MAS).

ABMs integrate the first two models and are represented by the third type of models. Several researchers have constructed land use scenarios and estimated discharge from a catchment by using hydrological or agro-economic models (e.g. Legesse et al., 2003; Narendra et al., 2003; Jewitt et al., 2004). In an ABM perspective different scenarios of land use and land use change decisions are made by the agents (farm managers) in the virtual laboratory of the $\mathrm{ABM}$ model that mimics the actual situation through the rules and communication system conceptualised by multidisciplinary scientists based on the real situation of the environment.

Among the different land use scenarios that are simulated, one is able to identify the scenario which is the most environmentally sustainable including the one that realises the most optimum water productivity. Thus, the aim of this study was to conceptualise the agents and their interaction with the biophysical and socio-economic factors in the Modder River basin which will contribute towards the development of an agent-based model.

\section{Materials and methods}

\subsection{The Modder River Basin}

The Modder River basin is located within the Upper Orange Water Management Area to the north and east of the city of Bloemfontein in central South Africa. It has a total area of approximately 1.7 million ha and is divided into three reaches, namely the Upper, the Middle and the Lower Modder River (Figure 1). The Modder river basin is characterised by low and erratic seasonal rainfall with annual average amount of about $550 \mathrm{~mm}$. In this basin irrigated agriculture is the main sector with the highest water requirement. 
The total water requirement for both irrigation and urban use in the three reaches of the Modder River basin is given in Figure 2. Given the limited availability of water resources in the catchment it appears that only a portion of the irrigation demand, estimated at 55.5 per cent, can be met by the existing water supply (see Figure 3), whereas 97.7 per cent of the urban water requirement does seem to be met, as indicated in Figure 3. It is also estimated that 74 per cent of the total water requirement is for irrigation purpose compared with 26 per cent for urban water need. Water requirements for irrigation place a large demand and pressure on water resources of the catchment.

Irrigation farming in the catchment is mainly practiced in the lower reaches of the river. Most of the land use in the upper and middle Modder River is dominated by degraded grassland. Due to the low rainfall and soil type which is prone to crusting, farmers frequently encounter scarcity of soil water which results in low crop yields and rainwater productivity. These climatic and environmental situations are believed to be discouraging small scale farmers to produce their own food.

\section{Figure 1 The topography of the Modder river basin and its three reaches.}

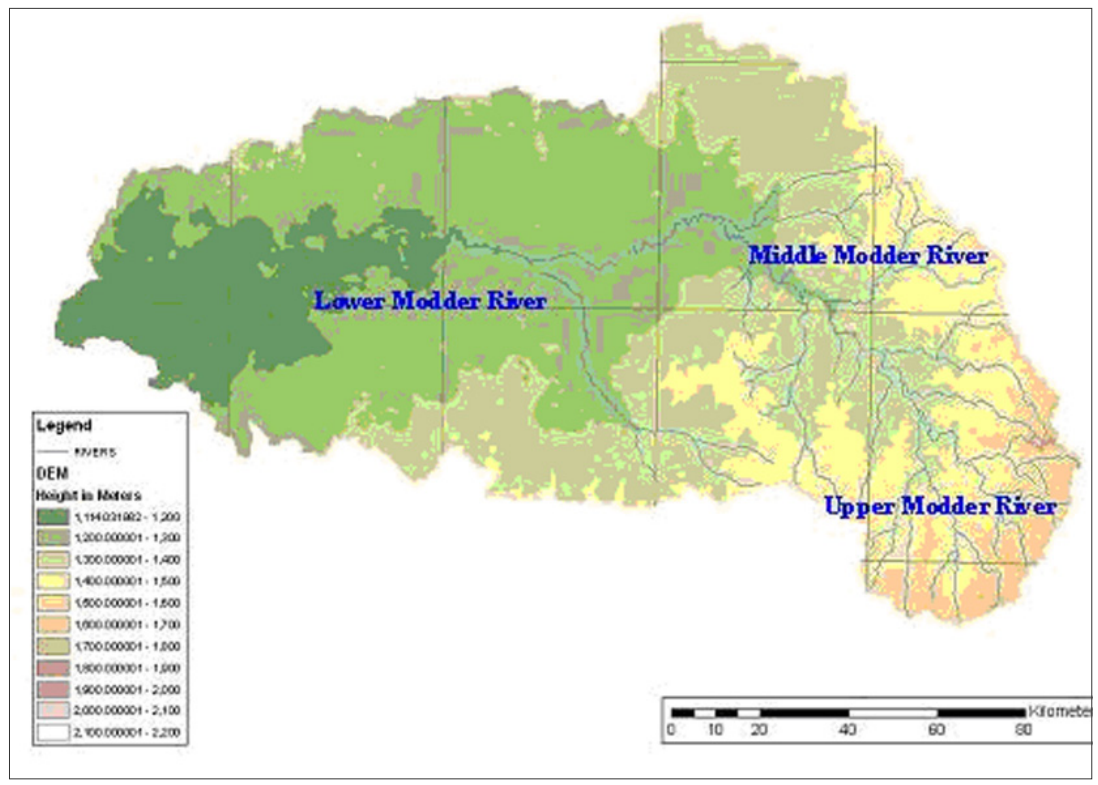


Figure 2 Water requirements for irrigation and urban use in the Modder river catchment (based on data from Rossouw, 2005).

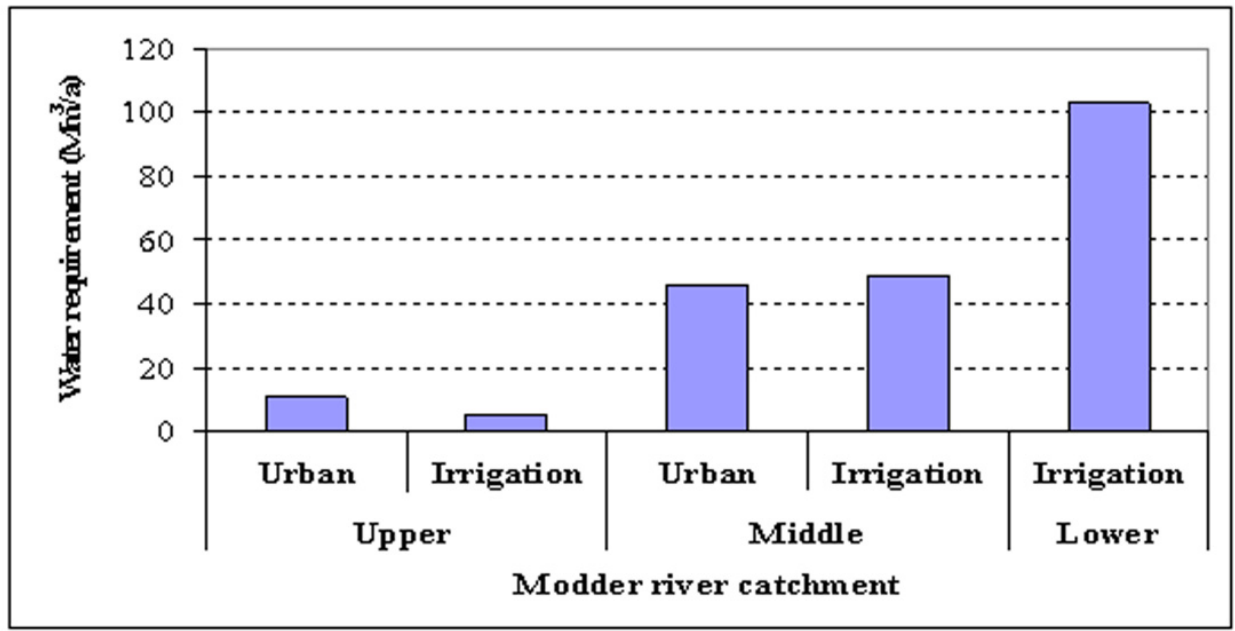

Figure 3 Water requirement and supply for irrigation and urban use in the Modder river catchment (based on data from Rossouw, 2005).

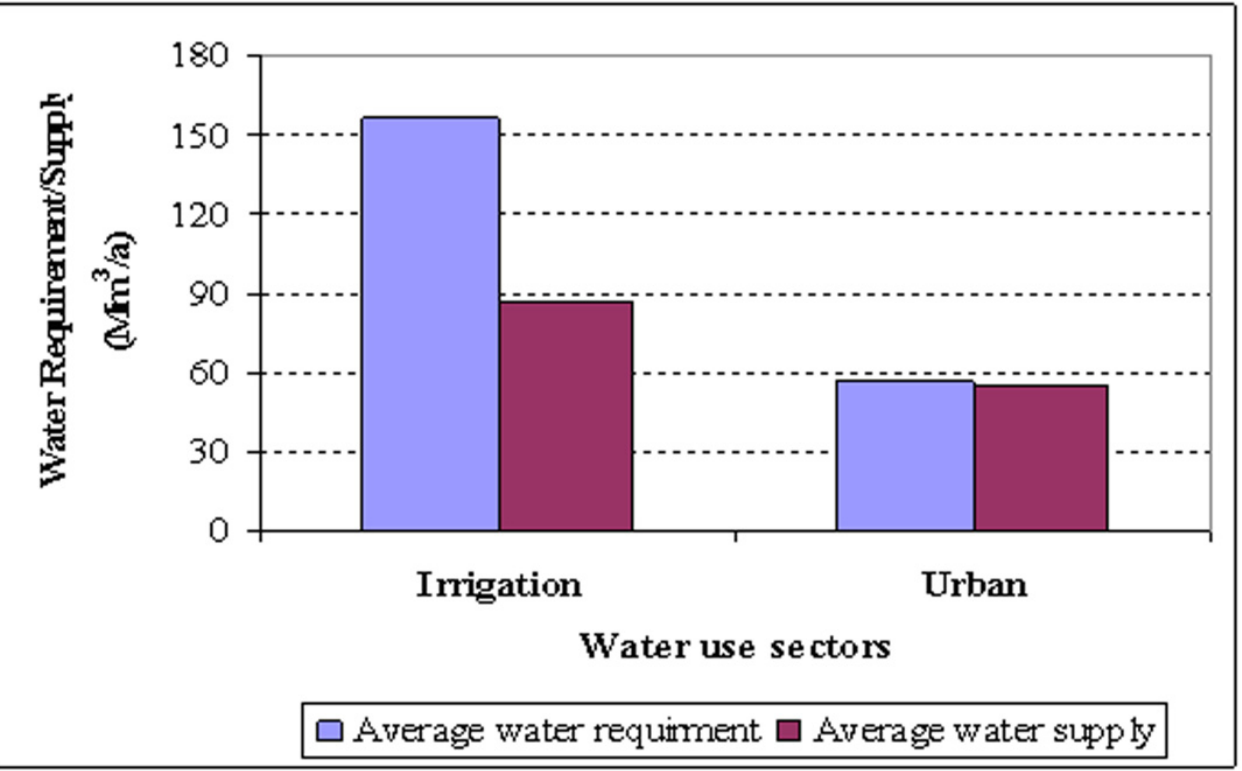




\subsection{Development of the Conceptual Model}

The importance of a conceptual model has been described as "to state the model's objectives, bound the system of interest, categorize its components, identify relationships, and to describe the expected patterns of the model's behaviour" (Purnomo \& Guizol, 2006). The conceptualisation of the impact of land use/cover change includes identifying relations between socio-economic, biophysical and environmental factors within the framework of agent-based modelling and multi-agent systems for natural resource management.

Creation of the conceptual model was done through series of meetings and workshops held among the team members of the project. These meetings and workshops were used to visualize, using a brain mapping technique, the relationships and interactions between the different factors, namely socio-economic, biophysical and environmental factors.

\subsubsection{Biophysical factors}

Biophysical factors, such as climate, soil, topography and vegetation are some of the major factors that greatly affect runoff that would be produced from a specific catchment (Peugeot et al., 1997; Manoj et al., 2004). Rainfall and evapotranspiration (ET) are the main components of the climate that have a significant influence on the water balance of a catchment. High rainfall generally contributes to increased stream flow while in contrary high ET reduces the amount of overland water considered as blue water (Jewitt et al., 2004).

Soil physical and chemical properties such as soil texture and infiltration rate affect the amount of surface water run-off considerably. Soils which are fine textured and prone to surface crusting and soils with low infiltration rate contribute to high surface runoff.

On the other hand, sandy soils and soils with high infiltration rate reduce runoff and thereby stream flows. Different vegetations and land use types also affect the overland water in different ways. Vegetations mainly affect the evapotranspiration and runoff. Land uses for varying crop types on different slopes result in varying runoff amounts. For instance, in arid zones where rainfall is insufficient for crop production, water conservation techniques used for improving moisture deficiency may be responsible for decreased stream flow.

\subsubsection{Socio-economic factors}

Socio-economic factors, such as income, market opportunity, 
education level, access to labour and land; and intensity and frequency of interaction with other agents greatly influence the behaviour of agents to make a decision on land use (Lambin et al., 2003). Besides the behavioural change, a farmer (an agent) requires sufficient income, know-how, market opportunity and enough labour (depending on the need of the new enrolment) to make a decision on the land use. Age, sex and cultural taboos and beliefs also contribute a great deal to the behaviour of an agent. Thus, all those social factors that would contribute to the change in land use consequently affect the water resource of a specific catchment including downstream affects.

\section{Results and discussion}

\subsection{Conceptualisation of the interactions}

Various interactions between the different factors within the catchment were identified and are given in Figure 4. Major actors/ agents and their relationships and interactions, their interest of interaction, methods of interactions as well as the impact of the interactions on land use/land cover change should be thoroughly investigated and described. Interactions between agents and the environment should also be investigated, as well as agents' behaviour, i.e. their reactive action to make decision. Here it was assumed that agent's reactive action is built from knowledge acquired by the interactions.

Finally, multidisciplinary scientists, through discussion, constructed the conceptual model that helps to develop ABM of land use/land cover change for the catchment. The conceptual model given in Figure 4 shows the basic research questions and goals, the elements of the system (i.e. agents and other features), the relevant behaviours of the agents, and the measurable outcomes of interest.

\subsection{Description of the conceptual model}

Figure 4 presents the conceptual model for the quaternary catchment of $\mathrm{C} 25 \mathrm{~A}$. It can be seen from the figure that the environment encompasses all biophysical resources, agents and socioeconomic activities taking place in the catchment. In this catchment external as well as internal agents are said to exist and interact with each other. The external agents are represented by those agents coming into the catchment from outside of the boundary of the catchment such as researchers, extension workers, and government and non-government agents.

Agents located inside the catchment are mostly represented by 
households and individual farmers or farm mangers. Some agents like traders and casual workers can exist internally as well as externally. In our case agents like agricultural researchers and agricultural extension workers have goals to improve the livelihood of small scale farmers through improved technologies that improve rainwater productivity and/or irrigation water productivity. These agents interact with the farmers through training, workshops and demonstration experiments. Similarly other agents, such as environmentalist and nature conservationist have goals to protect the natural resource of the environment and ensure its sustainable utilisations by applying policy and law.

On the upstream side of catchment the conceptual model shows the influential agent types and attributes. It also shows the catchment demography, agent's social status and economical and labour capacity. These all have a significant effect on land use/ cover changes. Agents represented by farmers or farm managers, after a complex interaction with similar agents and/or other agents and with the environment will be assumed to undergo a behavioural change. These agents who acquired an immense knowledge from the interaction and the environment can react individually or else as a group.

A reaction may lead to a decision towards changing of land use, for instance adoption of RW (see Figure 5). Land use changes could occur spatially as well as temporally within the environment.

The environment contains spatially different soil types and topographic features which can be considered static for a considerable period. These in combination with the climatic factors which are assumed to be homogenous over the catchment can contribute for the generation of different amounts of runoff depending on the land use, soil type and topography of the explicitly situated land/farmland.

Thus, the model was conceptualised to capture all the above mentioned processes. The socioeconomic factors and their interaction that lead to decision in land use change could be captured by the ABM module while the biophysical factors that have direct impact on runoff and stream flow could be handled by the hydrologic module which will be integrated in the model.

The analysis for the downstream catchment has similarity with the upstream one. But for the downstream part the model flow is the inverse of the upstream one. All land use decisions taking place in the downstream catchment emanates from the availability of water in the Rustfontein dam and the amount of water discharged from it. Thus, the complete analysis for the downstream catchment depends on the results of the upstream catchment. 
Figure 4 Conceptual model of land use decision and its impact on water resources.

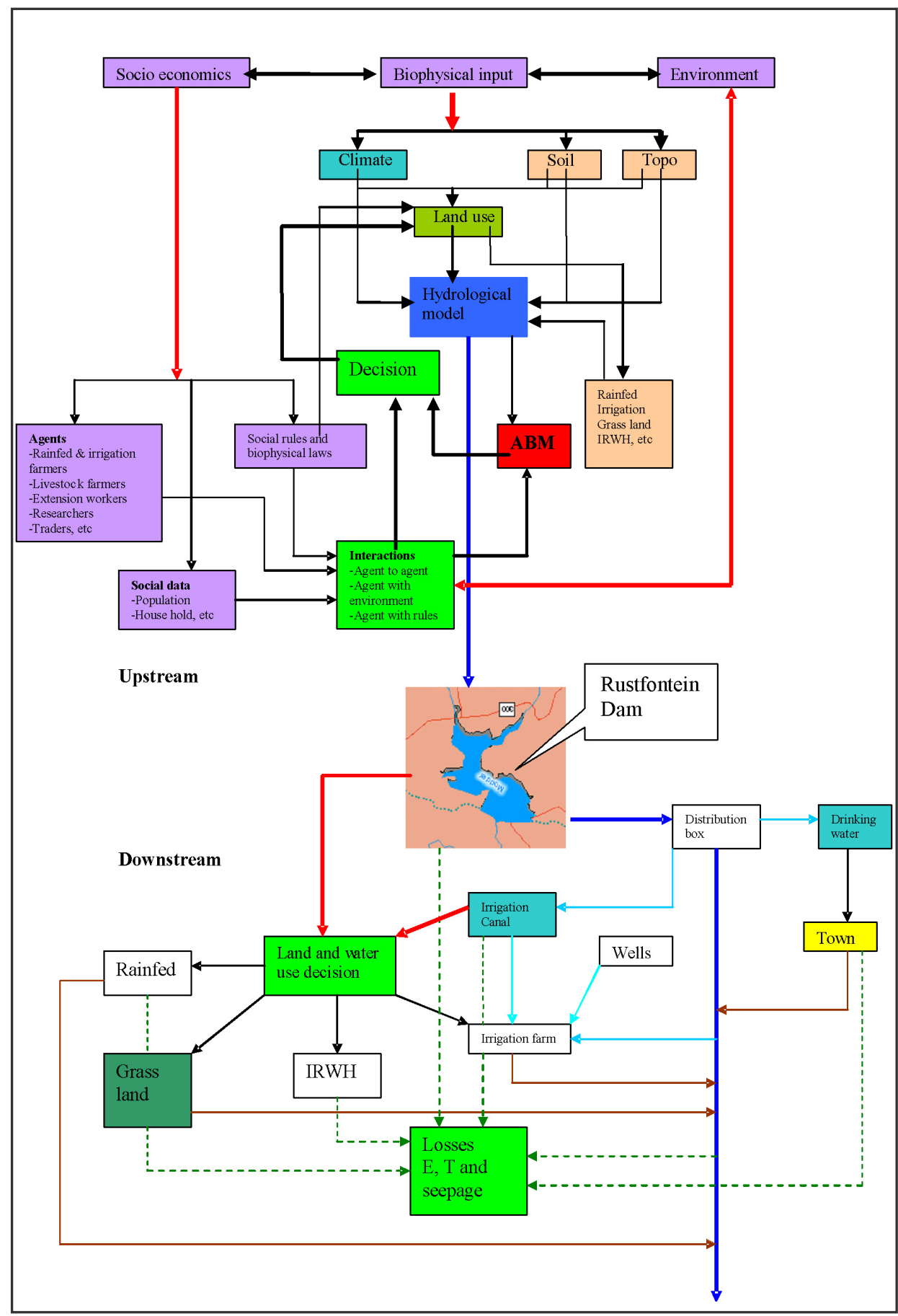


Figure 5 Flow chart showing agent to agent interactions in the process of Infield Rain Water Harvesting (IRWH) adoption.

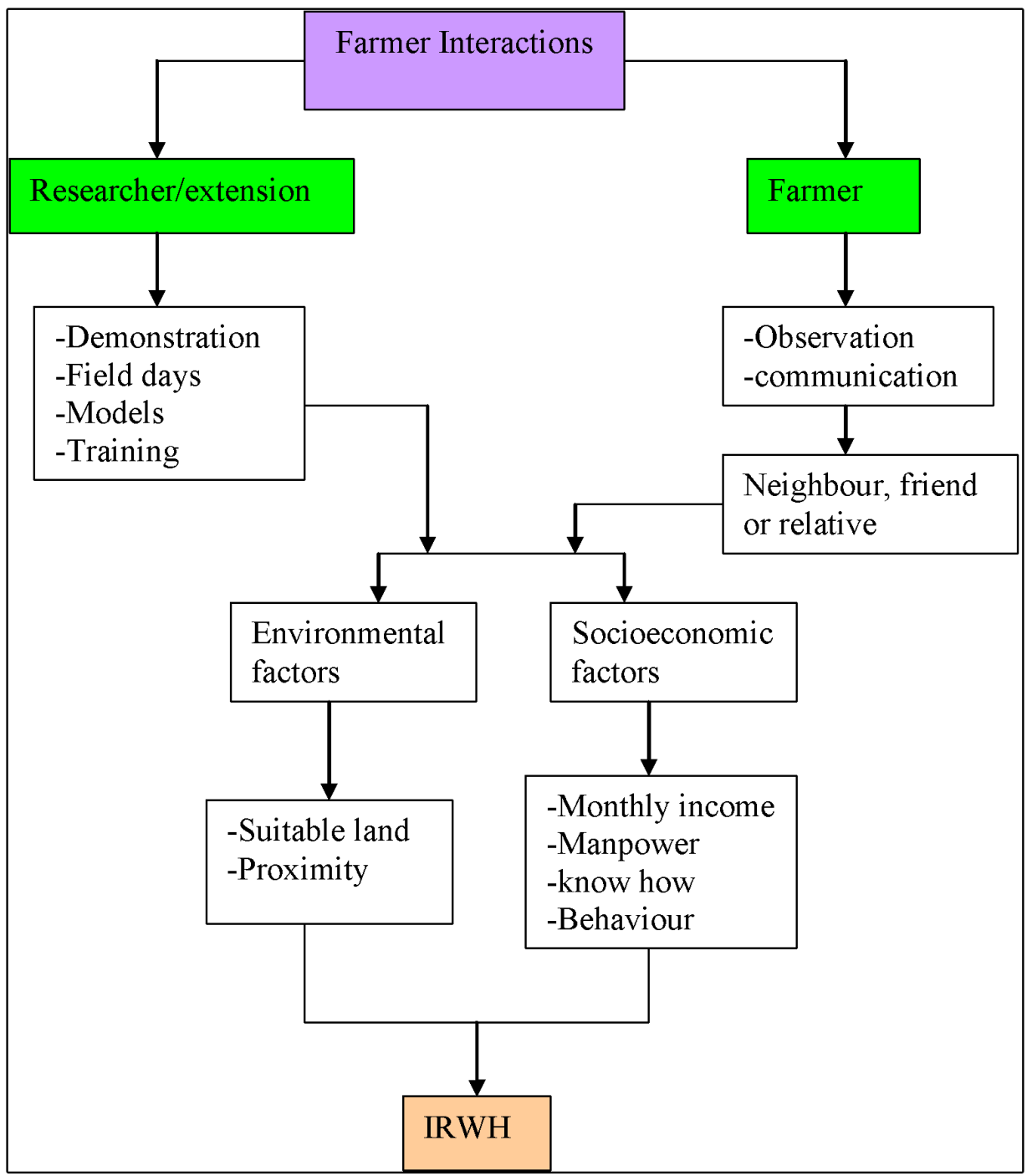

As indicated in Figures 4 and 5, interactions can occur between agents (agent-agent interaction) and between agents and their environment. In this study, it was assumed that there is an interaction between agents, agents and social rules, and between agents and environment. For example, agent to agent interactions and rule of communications in adapting IRWH, as shown in Figure 5 , can be described as follows. 


\section{Researcher/extension worker with farmer}

These agents mainly interact and communicate through field days, demonstration experiments, workshops and through trainings organised by the research and extension institutions. The training includes teaching with models and field practical works on IRWH. Farmers then participate in the mentioned interactions and adopt IRWH.

\section{Farmer to farmer}

In this type of interaction, the communication mainly takes place in different forms, such as observation, especially from neighbouring farmers; and hearing about the benefits from friends and relative farmers. This method includes only those farmers neighbouring a farmer who practices IRWH one year or season ahead of them. The farmers who decide to change their traditional farming to IRWH should be at least in near proximity to the IRWH practicing farmer's field or else be a friend/relative to him. In both cases, farmers need not only to change their behaviour but also need to fulfil the initial conditions in order to adopt IRWH, such as sufficient monthly income to run the enterprise, basic technical know-how in practical crop husbandry, own suitable land for IRWH, have sufficient labour force, possibly not involved in other agriculture enterprises such as livestock husbandry.

\section{CONCLUSION}

The scarcity of available water resources and the variability of rainfall in South Africa pose a number of challenges in the country's need for economic growth and development. Typical challenges include the increased population growth and subsequent increasing demand and competition for water in both urban and rural areas. Traditional irrigated agriculture is the largest user of water resources. In the Modder river basin, small scale farmers are being introduced to improved surface water management practices by collecting rainwater onsite as well as storing it and diverting it to crop fields. The increasing cost of irrigation water and associated agricultural inputs will also put pressure on commercial farmers to seek alternative and cheaper water sources, such as rainwater, as a supplement to water obtained from rivers. This will bring about land use changes in the catchment which would, most likely, affect the amount of inflow into dams and reservoirs.

The conceptual model presented in this paper was an effort towards the understanding of the different factors that are the driving forces 
and their interactions in the decision of land use and its impact on water resources of the Modder River Basin. The model illustrates the main domains of the environment, the socioeconomic factors and the agents that are interacting and making decisions on land use changes. This model will help us to develop the ontological model which is the prerequisite in the development of the ABM, which will consist of a hydrological module and a socio-economic module. This, however, is a primary effort in the development of an ABM within the Modder River Basin system and needs continues refinement for optimum functionality and simulation of the real world.

\section{REFERENCES}

Becu, N., Perez, P., Walker, A., Barreteau O. and Le Page, C. 2003. Agent based simulation of a small catchment water management in northern Thailand. Description of the CATCHSCAPE model. Ecological Modelling 170:319-331.

Berger, T., Couclelis, H., Manson S.M. and Parker, D. C. 2002. Agentbased models of LUCC. In: Agent-Based Models of Land use and Land-Cover Change. Eds. D. C. Parker, T. Berger and S. M. Manson. Report and review of an International Workshop, Irvine, California, USA, October 4-7, 2001, pp 1-6.

Calder, I.R. 2003. Assessing the water use of vegetation and forests: development of the Hydrological Land Use Change (HYLUC) model. Water Resources Research 39:1318.

Couclelis, H. 2001. Why I no longer work with agents: A challenge for ABMs of human environment interactions. Eds. D.C. Parker, T. Berger and S.M. Manson. Proceedings of an International Workshop, October 4-7, 2001, Irvine, California, USA.

Deadman, P.J. 1999. Modelling individual behaviour and group performance in an intelligent agent-based simulation of the tragedy of the commons. Journal of Environmental Management 56:159-172.

Feuillette, S., Bousquet F. and Le Goulven, P. 2003. SINUSE: a multiagent model to negotiate water demand management on a free access water table. Environmental Modelling \& Software 18:413427.

Jewitt, G.P.W., Garratt, J.A., Calder, I.R. and Fuller, L.2004. Water resource planning and modelling tools for the assessment of land use change in the Luvuvhu Catchment, South Africa. Physics \& Chemistry of the Earth 29: 1233-1241.

Lambin, E.F., Geist H.J. and Lepers, E.L. 2003. Dynamics of Land use 
and Land-Cover Change in Tropical Regions. Annu. Rev. Environ. Resour. 28: 205-241.

Legesse, D., Vallet-Coulomb C. and Gasse, F. 2003. Hydrological response of a catchment to a climate and land use changes in Tropical Africa: Case study of South Central Ethiopia. Journal of Hydrology 275:67-85.

Manoj, K.J., Kothyari U.C. and Ranga Raju, K.G. 2004. A GIS based distributed rainfall-runoff model. Journal of Hydrology 299:107-135.

Narendra, K.T., Beale, G., Dawes, W., Vaze, J., Murphy, B., Barnett, P., Rancic, A., Evans, R., Geeves, G., Rassam, D.W. and Miller, M. 2003. Predicting the effects of land use change on water and salt balance-a case study of a catchment affected by dryland salinity in NSW, Australia. Journal of Hydrology 283:67-90.

Ostrom, E., Gardner R. and Walker, J. 1994. Rules, games and common-pool resources. Ann Arbor: University of Michigan Press.

Peugeot, C., M. Esteves, S. Galle, Rajot. J.L. and Vandervaere, J.P. 1997. Runoff generation processes: results and analysis of field data collected at the East Central Supersite of the HAPEX-Sahel experiment. Journal of hydrology, 188-189:179-202.

Purnomo, H. and Guizol, P. 2006. Simulating forest plantation comanagement with multi-agent system. Mathematical \& Computer Modelling 44:535-552.

Rossouw, J. 2005. Development of Catchment Management Strategy (CMS) for the Modder and Riet Rivers in the Upper Orange Catchment Management Area: Water Balance Analysis. First draft report. BKS Pty Ltd.

Woyessa, Y.E., Pretorius, E., van Heerden, P.S., Hensley, M. and van Rensburg, L.D. 2006a. Impact of land use on river basin water balance: A case study of the Modder River Basin, South Africa. Comprehensive Assessment Research Report 12. Colombo, Sri Lanka: Comprehensive Assessment Secretariat. 